\title{
Implikasi Pendidikan Nonformal Pada Remaja
}

\author{
Arabiatul Adawiyah \\ Sulfasyah \\ Universitas Muhammadiyah Makassar \\ sulfasyah@unismuh.ac.id \\ Jamaluddin Arifin \\ Universitas Muhammadiyah Makassar \\ jamaluddinarifin@unismuh.ac.id
}

\begin{abstract}
ABSTRAK
Pendidikan adalah hal yang utama didalam kehidupan era skarang ini.pendidikan dapat diperoleh melalui jalur pendidikan formal, informal dan nonformal. Taman pendidikn al-quran merupakan lembaga pendidikan nonformal yang ikut serta dalam memajukan dan mencerdaskan anak bangsa terutama remaja,baik pendidikan moral maupun agama.penelitian ini bertujuan untuk mengetahui i) Perilaku sosial remaja ditaman pendidikan al-quran ii) Pengaruh dan faktor penyebab perilaku sosial remaja dalam masyarakat.penelitian yang dilakukan merupakan penelitian sosial budaya metode penelitian yang digunakan adalah penelitian deskriptif kualitatif dengan cara memilih beberapa informan yang telah ditentukan oleh peneliti. Penelitian ini menunjukkan bahwa taman pendidikan al-quran memiliki banyak pengaruh bagi remaja yaitu: i) remaja tidak hanya diajarkan membaca dan menulis al-quran tetapi dia juga diajarkan bagaimana berperilaku yang baik, sopan dalam berbicara serta menghargai orang yang lebih tua ii) adapun faktor penyebab perilaku sosial remaja yang ada di taman pendidikan al-quran adalah faktor internal (dari dalam diri remaja itu sendiri)seperti malas ikut mengaji serta kurangnya dorongan dan perhatian dari orang tua remaja,dan faktor eksternal (pengaruh dari luar atau lingkungan) yaitu adanya pengaruh dari teman sebayanya dan terkadang remaja bermasa bodoh dan malas pergi mengaji karena terpengaruh oleh teknologi yang semakin berkembang. maka dapat disimpulkan bahwa perilaku remaja yang ikut di Taman Pendidikan Al-quran sangat dipengaruhi oleh dorongan orangtua dan didikan
\end{abstract}

Kata Kunci: Taman Pendidikan Al-quran, Perilaku Sosial Remaja

\section{PENDAHULUAN}

Pendidikan adalah hal mutlak yang wajib dimiliki oleh semua individu, di dalam setiap ajaran agama menganjurkan agar setiap individu wajib berusaha untuk mendapatkan pendidikan. Pendidikan dapat diperoleh melalui jalur formal, non formal dan informal. Pendidikan dalam lingkungan keluarga (In formal) memiliki peranan yang sangat penting. Ini karena setiap individu mendapatkan pendidikan yang pertama berasal dari lingkungan keluarga.Di dalam keluarga individu dididik untuk menjadi seorang anak yang baik, yang tahu sopan santun dan etika serta mempunyai moral sifat yang terpuji. Selain dari keluarga pendidikan dapat diperoleh pula dari lingkungan formal, dalam hal ini sekolah atau lembaga formal lainnya yang berkompeten dalam bidang 
pendidikan.Pendidikan formal yang sering disebut pendidikan persekolahan, berupa rangkaian jenjang pendidikan yang telah baku misalnya SD, SMP, SMA dan PT (Perguruan Tinggi). Pendidikan formal lebih difokuskan pada emberian keahlian atau skill guna terjun ke masyarakatDalam lingkungan formal ini setiap individu akan mendapatkan pendidikan yang lebih luas mengenai pedoman dan etika moral kemanusiaan untuk bekalnya dalam menghadapi pergaulan di masyarakat. Lingkungan ketiga yang menjadi penentu sukses tidaknya pendidikan iindividu adalah lingkungan masyarakat ( Nonformal), lingkungan ini menuntut pengaplikasian pendidikan yang telah didapat oleh seorang individu baik dari lingkungan keluarga maupun dari lingkungan formal.

Pendidikan non formal merupakan mekanisme yang memberikan peluang bagi setiap orang untuk memperkaya ilmu pengetahuan dan teknologi melalui pembelajaran seumur hidup. Pendidikan nonformal adalah setiap kesempatan dimana terdapat komunikasi yang teratur dan terarah di luar sekolah. Dalam pergaulannya di masyarakat, individu harus mempunyai etika dan sopan santun. Dari ketiga penjelasan diatas jelas bahwa ketiganya sangat berkaitan erat dengan kehidupan remaja, Coobs (1973) dalam D Sudjana (2003) membedakan ketiga jenis pendidikan itu sebaga berikut: pendidikan formal adalah kegiatan yang sistematis, berstruktur, bertingkat, berjengjang dimulai dari sekolah dasar sampai dengan perguruan tinggi dan yang setara dengannya.

Di kelurahan Tassililu Kecamatan Sinjai Barat Kabupaten Sinjai telah berdiri pendidikan, TPQ (Taman Pendidikan Al- Qur'an ) yang dijadikan sebagai salah satu lembaga pendidikan yang bergerak pada perkembangan pendidikan al-Qur'an. Banyak pihak yang menaruh harapan di TPQ. Taman pendidikn al-quran atau TPQ merupakan lembaga pendidikan nonformal yang ikut serta dalam memajukan dan mencerdaskan anak bangsa terutama remaja yang ada di kecamatan sinjai barat kabupaten sinjai. Dengan demikian TPQ memiliki peranan untuk membentuk remaja berakhlak mulia dan bermartabat. TPQ diharapkan dapat menjadi sebuah tempat pencerahan baik pendidikan moral maupun agama.

Sebelum anak melanjutkan ke jenjang sekolah dasar anak sudah mulai di beri dorongan untuk berangkat ke TPQ tersebut dalam rangka penanaman moral sejak dini dan untuk mengajarkan kepada anak akan pentingnya pengetahuan keagamaan dalam hal ini membaca al-quran. Dengan perkembangn teknologi yang sangat canggih remaja sekarang terkadang malas dan mengacuhkan hal tersebut. para orangtua harus ikut 
berpartisipasi dalam hal pendidikan TPQ agar benar-benar menumbuhkan kesadaran kepada anaknya sejak dini akan pentingnya nilai-nilai keagamaan.

\section{LANDASAN TEORI}

Pendidikan Informal, Formal, dan Nonformal 1) Lingkungan In Formal (Keluarga) Lingkungan nonforml (keluarga) Adalah lingkungan atau tempat berkumpulnya individu satu dengan individu lainnya dalam satu keluarga. Keluarga merupakan pengelompokan primer yang terdiri dari sejumlah kecil orang karena hubungan semenda dan sedarah.2) ( Sekolah) Lingkungan formal (sekolah) Adalah lingkungan tempat berkumpulnya individu satu dengan individu lain di sebuah tempat belajar/sekolah.3)Lingkungan nonformal (masyarakat) Adalah lingkungan atau tempat berkumpulnya individu satu dengan individu lainnya dalam satu lingkungan, baik dalam lingkungan desa satu ataupun dengan desa lainnya. Landasan Taman Pendidikan AlQuran (TPQ) dalam pandangan human adalah untuk menyiapkan anak didik agar menjadi generasi muda yang kur'ani, komitmen dengan Al- quran dan menjadikan al- quran sebagai bahan bacaan dan pandangan hidup sehari- hari. Oleh karena itu pendidikan berbasis nilai dalam hal taman pendidikan al-quran atau TPQ dalam program pendidikan nonformal harus mulai dikembangkan baik saat ini maupun dimasa yang akan datang, mengingat taman pendidikan al-quran atau TPQ saat ini sudah mulai terkikis oleh berkembangnya kemajuan teknologi dan akulturasi kebudayaan asing yang masuk ke negeri ini.

Sosialisasi adalah satu konsep umum yang bisa dimaknakan sebagai sebuah proses di mana kita belajar melalui interaksi dengan orang lain, tentang cara berpikir, merasakan, dan bertindak, di mana kesemuanya itu merupakan hal-hal yang sangat penting dalam menghasilkan partisipasi sosial yang efektif. Sosialisasi merupakan proses yang terus terjadi selama hidup kita. Salah satu teori peran yang dikaitkan dengan sosialisasi ialah teori George Herbert Mead.Dalam teorinya yang diuraikan dalam buku Mind, Self, and Society (1972), Mead menguraikan tahap pengembangan diri manusia.Manusia yang baru lahir belum mempunyai diri. Diri manusia berkembang secara bertahap melalui interaksi dengan anggota masyarakat lain. Menurut Mead pengembangan diri manusia berlangsung melalui tahap-tahap sebagai berikut :1) Tahap persiapan (preparatory stage)Tahap ini dialami sejak manusia dilahirkan, saat seorang anak mempersiapkan diri untuk mengenal dunia sosialnya.Pada tahap ini juga anak mulai melakukan kegiatan meniru meski tidak sempurna. Dalam tahap ini, individu sebagai 
calon anggota masyarakat dipersiapkan dengan dibekali nilai-nilai dan norma-norma yang menjadi pedoman bergaul dalam masyarakat.2) Tahap Meniru (Play Stage)Tahap ini ditandai dengan semakin sempurnanya seorang anak menirukan peran-peran yang dilakukan oleh orang dewasa. Pada tahap ini mulai terbentuk kesadaran tentang nama diri dan siapa nama orang tuanya, kakaknya, dan sebagainya.3) Tahap Siap Bertindak (Game Stage)Peniruan yang dilakukan sudah mulai berkurang dan digantikan peran yang secara langsung dimainkan sendiri dengan penuh kesadaran. Kemampuannya menempatkan diri pada posisi orang lain pun meningkat, sehingga memungkinkan adanya kemampuan bermain secara bersama-sama.4) Tahap Penerimaan Norma Kolektif (Generalizing Stage)Pada tahap ini seseorang telah dianggap dewasa.Dia sudah dapat menempatkan dirinya pada posisi masyarakat secara luas. Dengan kata lain, dia dapat bertenggang rasa tidak hanya dengan orang-orang yang berinteraksi dengannya, tetapi jugadengan masyarakat secara luas.

\section{PEMBAHASAN}

Pada masa sekarang ini pendidikan merupakan suatu kebutuhan primer, pendidikan memegang peranan penting, menurut baharuddin salam (2002:14) mengemukakan bahwa keluarga merupakan lembaga pendidikan yang pertama dan utama secara wajar melalui media permainan. Dikelurahan Tassililu telah berdiri pendidikan nonformal yang bergerak pada pendidikan membaca dan menulis al-quran mulai dari jus ammah sampai mahir membaca al-quran, dari anak mulai umur 6 sampi 17 tahun mereka diharuskan mempelajari al-quran karena menurut masyarakat, guru mengaji dan orang tuanya apabila mereka ingin melanjutkan pendidikan ke sekolah menengah pertama persyaratannya adalah harus mahir membaca al-quran. Kegiatan menulis dan membaca alquran dilaksanakan setip hari dua kali dalam sehari antara pukul 6 pagi dan jam 2.30.tingginya antusias dan minat mengaji anak-anak tidak luput dari dorongan dan arahan dari kedua orang tuanya dan juga anak- anak tersebut tidak terganggu aktifitas belajarnya disekolah karena dilakukan dilingkungan nonformal atau di masyarakat. walaupun kadang terlihat anak-anak lelah namun semua itu hilang karena melihat temantemannya bersama-sama ikut mengaji selain mengaji dia juga bisa bertemu dan bermain bersama teman sebayanya.

Walaupun menurut gurunya dalam mengajarkan anak membaca al-quran biasanya susah-susah gampang karena ada yang cepat memahami bacaan al-quran, ada pula yang lambat memahami bacaan al-quran yang lambat biasanya diberikan pendidikan 
yang khusus agar anak tidak minder ketika melihat temannya yang sudah mahir membaca al-quran disinilah pentingnya dorongan dan motivasi yang diberikan kepada keluarga dan gurunya. Orang tua memegang peranan penting dalam hal keberhasilan dan perkembangan anak sedangkan tugas dan tanggung jawab untuk hal tersebut adalah tugas bersama antara orang tua, masyarakat, serta anak itu sendiri, secara alami anak lahir dan dibesarkan dalam keluarga, sejak lahir anak sudah dipengaruhi oleh lingkungan yang terdekat yaitu keluarga.

Pendidikan yang diterima sebelum memasuki pendidikan forml adalah pendidikan nonformal yang bersumber dari keluarga dan lingkungan masyarakat, disinilah awal pembentukan karakter dan kepribadian anak namun tidak semua lingkungan yang mendukung pendidikan anak, ada lingkungan yang memberi pengaruh negatif kepada anak yang mengganggu proses pembelajaran anak.

Pendidkan di dalam masyarakat tidak hanya berfungsi sebagai penanaman sikap saja tetapi bagaimana kita diajarkan nilai-nilai dan norma mereka juga diajarkan bagaimana bersikap sopan kepada orang lain, disipli dan juga bertanggung jawab dan juga memliki akhlak yang baik utamnaya remaja yang ada di kelurahan tassililu, dan pengaplikasianya dalam kehidupan masyarakat sehingga mereka paham mana yang harus di lakukan dan tidak boleh dilakukan serta menghargai orang yang lebih tua dari kita dan juga sebagai pengganti pendidikan formal, baik untuk anak didik dalam ha kepercayaan terhadap tuhan yang maha esa, mensejahterakan dirinya dan keluarganya.jadi pendidikan dapat disimpulka bahwa: 1) Suatu proses pertumbuhan yang menyesuaikan dengan lingkungan. 2) suatu pengarahan dan bimbingan yang diberikan kepda anak dalam pertumbuhannya. 3) suatu usaha sadar untuk menciptakan suatu keadaan atau situasi tertentu yang di kehendaki oleh masyarakat. 4) suatu pembentukan kepribadin dan kemampuan anak dalam menuju kedewasaan.

Pendidikan adalah hal yang paling utama yang dimiliki oleh seorang anak terutama membaca al-quran yang harus diajarkan sejak dini hingga iya beranjak dewasa. Keluarga merupakan faktor yang mempengaruhi perilaku anak, tidak mengherankan bahwa nilai- nilai, konsep diri atau pribadi dipengaruhi oleh keluarga dan pergaulan kita, keluarga bertanggung jawab terhadap proses sosialisasi dalam penerusan akan nilai kultural dan nilai masyarakat. Ada dua faktor yang mempengaruhi perilaku sosial remaja yaitu faktor internal dan faktor eksternal. 1) Faktor internaladalah faktor yang datang dari dalam diri manusia itu sendiri, faktor- faktor tersebut dapat berupa insting, motif dalam dirinya, sikap serta nafsu. 2) Faktor eksternal Faktor eksternal adalah faktor yang berasal 
dari luar diri manusia yang dipengaruhi dan dapat dilihat dari lingkungan seseorang itu tinggal.lingkungan dibagi menjadi dua yaitu: lingkungan keluarga dan lingkungan masyarakat Keluarga merupakan faktor yang mempengaruhi perilaku seseorang, keluarga sebagai bagia dari faktor eksternal yang mempunyai pengaruh besar dalam pembentukan sikap dan perilaku anggotanya. Termasuk dalam pembentukan keykinan dan berfungsi langsung dalam menetapkan keputusan yang akan diambil. Dalam keluarga seharusnya anak sejak kecil suda diperkenalkan pada hal-hal keagamaan seperti mengikuti beca dan tulis al-quran di mesjid, rumah, maupun di lingkungan tempat ia tinggal serta mengajarkan agama yang dianutnya oleh guru, lingkungan maupun orang tunya. Ketersediaan guru merupakan faktor yang sangat penting dalam proses pembelajaran kehadiran guru yang memiliki kualitas dan kedisiplinan yang tinggi akan mempermudah tuntunan atau kebutuhan peserta didik akan mempermudah transformasi ilmu dari guru ke peserta didik ini menunjukkan adanya kesadaran yang memang telah tertanam sejak kecil dari dalam diri mereka yang di dapat baik dari keluarga, tokoh agama guru mengaji maupun lingkungan masyarakatnya.Keterkaitan antara Hasil Penelitian denga Teori Seperti teori Behavioristik tentang perilaku sosial Teori ini memusatkan perhatiannya kepada hubungan antara akibat dari tingkah laku yang terjadi di dalam lingkungan masyarakat.Di mana perilaku remaja merupakan faktor yang perlu di handari agar tidak meresahkan masyarakat Teori Behavioral sosiologi berusaha untuk menerangkan hubungan historis anatara akibat tingkah laku masa lalu yang terjadi dalam lingkungan aktor dengan tingkah laku aktor yang terjadi sekarang.Artinya, teori tersebut menerangkan bahwa tingkah laku yang terjadi dimasa sekarang merupakan akibat dari tingkah laku yang terjadi di masa sebelumnya.

\section{DAFTAR PUSTAKA}

Ambo Enre Abdullah, 2005. Pendidikan Di Era Ototnomi Daerah Gagasan Dan Pengalaman. Pustaka Timur : Yogyakarta

Ahmadi, Abu. 1999. Psikologi Sosial. Jakarta: PT Rineka Cipta.

Akbar dan Usman. 2011. Metode penelitian sosial. Jakarta: Bumi Aksara.

Barnadib, Imam. 1987. Pendidikan Perbandingan: Buku Dua Persekolahan dan Perkembangan Masyarakat. Yogyakarta:Andi Offset

Bagong Suyanto Dr. 2013. Masalah Sosial Anak. Jakarta: PT fajar interpratama mandiri Budiono.1997. Pendidikan Dan Perubahan Sosial Ekonomi. Jakarta: Aditya Media Basrowi, 2005.Pengantar sosiologi. Bogor. Ghalia Indonesia 
CiptaSoekanto,soerjono.1990. sosiologi suatu pengantar. Jakarta : rjawali pers

Dagun. 2002. Sosiologi keluarga. Jakarta :bineka cipta

Daradjat, Zakiyah dkk.Ilmu Pendidikan Islam.Jakarta:Bumi Aksara,1996.

Djamarah, Syaiful Bahri dan Azwan Zain. Strategi Belajar Mengajar.Jakarta: Rineka Cipta,2008.

Departemen Pendidikan Dan Kebudayaan.Kamus Besar Bahasa Indonesia.Jakarta:Balai Pustaka,1993.

Hadits No 4639.Shahih Bukhori Juz 15 Hal 439.

Hamdani.Filsafat Pendidikan Islam.Bandung:Pustaka Setia,1998.

Hidayatullah,Taufiq. Skripsi:Manajemen Pengembangan Taman Pendidikan Al-Qur'an Di TPQ Darussalam Di Desa Kolomagan Kec Wonodadi Kab Blitar. Kediri:Jurusan Tarbiyah STAIN Kediri,2010.

Johnson, paul Doyle.1986.Teori sosiologi klasik dan Teori sosiologi modernJakarta: PT.Gramedia

Kinlock. Graham C. 2005. Perkembangan Dan Pradigma Utama Teori Sosiologi. Bandung : Pustaka setiar

Muhammadiyahm, Marham dan Kamaruddin, Syahribulan. 2012. Sosiologi keluarga.Makassar.

Maryadi.(2005). Pemberdayaan potensi masyarakat melalui pendidikan kecakapan hidup.Diklus:Jurnal Pendidikan Luar Sekolah, Edisi 6, Th X, September 2005. Jurusan pendidikan luar sekolah, Fakultas Ilmu Pendidikan, Universitas Negeri Yogyakarta.

Moleong Lexv J. 2005. Metodologi penelitian kulitatif . Bandung: PT Remaja Rosdakarya.

Narwoko, Dwi j. 2007. Sosiologi teks pengantar dan terapanya. Jakarta kencana

Nasution 1998.Metode penelitian kuantitatif dan R\&D, Bandung: Afabeta

Quraisy, H., \& Babo, R. (2015).Pemberdayaan Masyarakat Desa Yang Buta Huruf.equilibrium, 3(2), 213-222.

Ritzer, George dan Goodman J. Douglas.2004.teori sosiologi modern. Jakarta: kencana Rumini,Sundari S.2004. perkembangan anak dan remaja. Jakarta: Rineka

Susyono, D. Dkk, (2007). Ilmu pendidikan. Fakultas Ilmu pendidikan,Universitas Negeri Yogyakarta. Yogyakarta: UNI Press.

Siswanto.2005. Panduan Praktis Organisasi Remaja Mesjid. Jakarta: Pustaka Al-kautsar. Stompka,piotr. 2007. Sosiologi perubahan sosial. Jakarta : penada media group 
Susilo Dwi klK Rachmad. 2008. Sosiologi lingkungan. Jakarta :PT Rajagrafindo persada

Tim Penyusun FKIP Unismuh Makassar. 2013. Pedoman penulisan skripsi. Makassae: FKIP Unismuh Makassar

W. A. Gerungan. 2004. Psikologi sosial. Bandung

Yusuf Muri. 2014. Metode penelitian. Jakarta : PT fajar interpratama Mandiri 